\title{
The Importance of Combining Basic and Applied Literature in Determining International Monetary Policy
}

William B. Joyce, (E-mail: wbjoyce@eiu.edu), Eastern Illinois University Stephen L. Woehrle, (E-mail: woehrs@mnsu.edu), Minnesota State University, Mankato

\begin{abstract}
This article is a discussion of the current state of knowledge about optimal monetary policy. The authors contrast basic and applied literatures. The basic literature is explicit about the frictions that generate a positive value for money and make it socially beneficial. The applied literature concentrates on ad hoc constructs. The authors discuss monetary policy lessons from each type of literature, as well as how the two distinct approaches may be usefully combined.
\end{abstract}

\section{INTRODUCTION}

1

$\mathrm{n}$ this article, the authors discuss the state of knowledge about optimal monetary policy. Papers on the "basic literature" of money are explicit about the frictions that make it possible for the price of money to be nonzero and make it possible for money to be socially beneficial. However, a larger body of work on monetary policy that is not explicit about monetary frictions is more aptly called "applied literature". Applied literature adopts ad hoc constructs like transaction technologies or preferences for real balances to rationalize the positive value of fiat money and its relatively low rate of return. In this article, the authors argue that recent work in the applied literature has important lessons for ongoing research in the basic literature and vice versa.

The authors begin with a review of applied and basic literatures, followed by suggestions for combining both into a more meaningful approach to monetary policy. First is a review of key papers in the applied literature. The main message of applied literature is that the existing theoretical benchmark for optimal monetary policy is the Friedman rule: The central bank should set monetary policy so that the return on money is equated to that of other assets. The government should use other instruments (like consumption taxes, wage taxes, and profit taxes) to collect its requisite tax revenues or to deal directly with inefficiencies like monopoly power or imperfect insurance. By definition, applied literature does not specifically describe the frictions that give rise to money demand on the part of individuals or society.

In the second part of this paper, the authors turn to basic literature. Basic literature is all about frictions. One would hope that basic literature would be able to tell us whether the Friedman rule is still optimal once one considers these frictions. Unfortunately, it does not. The authors propose that all of the basic literature suffers from at least one of two crucial defects. First, either directly or indirectly, all tax instruments beyond the inflation tax are eliminated from the model environments. Second, basic literature ignores the existence of other assets beyond money. A major lesson of applied literature is that these two omissions are likely to be important to the understanding of optimal monetary policy.

Both applied and basic literatures have made important contributions to the understanding of money, but each has flaws. In applied literature, there is no explicit description of the frictions that generate a demand for money, given the presence of other assets. In basic literature, there is only a smattering of work that endogenously generates a role for multiple assets without risk and none that allows for multiple tax instruments. It is the authors' belief that one of the main goals of monetary economists should be to better unite these two literatures. By uniting applied and basic literature researchers, the authors hope the problems afflicting both may be solved. The authors conclude with some 
suggestions for how to proceed in combining the two research approaches.

\section{LESSONS OF APPLIED MONEY LITERATURE}

This section is a discussion of applied money literature on optimal monetary policy. The government needs to finance a stream of purchases that may vary over dates and states. The question is how does the government optimally use the inflation tax to accomplish this task, given all of the other instruments at its disposal? Three different settings are considered, and it may be seen that the Friedman rule emerges as a remarkably robust prescription across these settings: "no heterogeneity and flexible prices", "no heterogeneity and sticky prices", and "heterogeneity and sticky prices".

\section{No Heterogeneity And Flexible Prices}

Friedman's classic 1969 essay argues that the goal of monetary policy is to equate the return of money and bonds-that is, to set the nominal interest rate to zero. As discussed in the Introduction, such a policy puts current costs and future benefits on the same footing. In this way, it cures the basic inter-temporal inefficiency associated with monetary exchange.

Phelps (1973) points out that the above intuition hinges on the government's having access to lump-sum taxation. Suppose a government has to raise a given amount of resources and it has access to two sources of revenue, the inflation tax and a labor income tax. Both taxes are fraught with distortion. Phelps argues that it is socially optimal for the government to trade off the two distortions, and that a socially optimal tax system would feature a positive nominal interest rate.

Phelps' discussion is largely an intuitive one. Chari et a1. (CCK, 1996) provide a complete formal analysis of the optimal taxation problem. They consider three different representative agent models of money demand: the money-in-the-utility function model of Sidrauski (1967), the cash-credit model of Lucas and Stokey (1987), and the shopping-time model of Kimbrough (1986). In all of these models, money has a lower return in equilibrium than bonds because money is assumed to be less costly to use in transactions than other assets, including other forms of government debt. However, the models do not provide an explicit micro-foundation for the superior role of money in transactions.

CCK assumes that the government has access to linear taxes on labor income and to the inflation tax. Both of these taxes are distortion. Phelps' intuition would imply that the nominal interest rate should be positive. But CCK show explicitly that Phelps' intuition is incorrect. In each of these three models, individual optimality implies a "money demand function" that describes how an individual's real money balances are related to his consumption, labor, and to the nominal interest rate. CCK prove that if the consumption elasticity of money demand is unity and money demand does not depend on labor supply, the optimal monetary policy is to set the nominal interest rate to be zero. Correia and Teles (1999) show that the Friedman Rule is valid as long as these conditions are satisfied by money demand in the neighborhood of the Friedman Rule (that is, when the nominal interest rate is near zero). Crucially, this result is valid regardless of the specifics of the model of money demand.

As they say themselves, CCK's finding is really a direct consequence of standard results from public finance. Diamond and Mirrlees (1971) establish the following key principle of public finance: Do not tax intermediate inputs. Money, of course, does not enter utility directly. Even in the money-in-the-utility function model, it is real balances, (not money itself) that enter utility. Instead, it is only an intermediate input into the purchase of consumption goods. Thus, we have a simple chain of logic. Money is an intermediate input. Basic public finance tells us that intermediate inputs should not be taxed. Thus, money should not be taxed. The nominal interest rate should be zero.

\section{No Heterogeneity And Sticky Prices}

CCK assumes that prices are fully flexible and that firms take prices as given. Yet, most central banks assume that monetary policy is effective only because firms set prices and at least some of them do not adjust prices fully in response to monetary policy shocks. Does the CCK analysis apply in a world with inflexible prices and 
monopolistically competitive firms? Corretia et al. (CNT, 2002) argues that the answer is yes, as long as the government has access to a sufficient number of tax instruments.

Money demand is motivated through the shopping-time technology of Kimbrough (1986).

Schmitt-Grohe and Uribe (2004) demonstrate that CNT's results are sensitive to these assumptions. In particular, they show that as long as the profit tax is bounded away from $100 \%$, and consumption taxes are fixed, it is optimal for the nominal interest rate to be positive and to be variable. There are two reasons for their finding. The first is that the government is trying to use the inflation tax to tax monopolistic profits. A second key force is that in Schmitt-Grohe and Uribe's (2004) model, the government cannot adjust the consumption tax in response to shocks. The government is forced to trade off between discrepancies caused by a fixed nominal interest rate and the inefficiencies generated by a positive nominal interest rate.

\section{Heterogeneity And Flexible Prices}

There is a plethora of discussion about the role of monetary policy in providing insurance against individualspecific shocks, concerning heterogeneity and flexible prices. da Costa and Werning (2003) analyze this question. They consider a Mirrleesian economy in which agents have fixed skills. The goal of the government in this world is to provide prenatal insurance: that is, to redistribute resources from those who are born with high skills to those who are born with low skills. da Costa and Werning consider two types of monetary models: a cash-credit model and a shopping-time technology. They prove that the Friedman rule is optimal in the first model if individual preferences are weakly separable between labor and the consumption goods. This result is an application of the Uniform Commodity Taxation Theorem of Atkinson and Stiglitz (1976). However, Golosov et al. (2003) prove that the Uniform Commodity Taxation Theorem applies when skills vary over time according to an arbitrary stochastic process. They conjecture that their result could be used to show that the Friedman rule is valid in the case in which skills vary over lime in the cash-credit model.

\section{Conclusions From Applied Literature}

The main message of the above literature is that the Friedman rule is optimal. Money is an intermediate good, and so it should not be taxed. Governments should correct inefficiencies due to imperfect insurance, market power, or nominal rigidities using other more direct instruments. This public finance intuition is a powerful one. It is likely to be at the heart of any analysis of optimal monetary policy.

However, the applied literature leaves many questions unanswered. The authors discuss three. One, what are the micro-foundations for the difference in returns between money and other assets? How are these micro-foundations likely to affect the nature of optimal monetary policy? Two, what is the source of the nominal rigidities? In particular, why are the government's monetary (and possibly fiscal) policy variables so much more flexible than firm prices? Three, da Costa and Werning (2003) and Golosov et al. (2003) discuss the response of monetary policy to skill shocks. But how should monetary policy respond to other individual-specific shocks (such as shocks to the marginal utility of consumption)? The hope is that the basic literature can provide answers to these and other related questions. In the next section, we assess the extent to which it does.

\section{BASIC LITERATURE CONTRIBUTIONS}

Basic literature focuses primarily on the overlapping-generations model of money. Since the publication of Kiyotaki and Wright $(1989,1991)$, the situation has changed dramatically. The new paradigm in the basic money literature is the random-matching model of Kiyotaki and Wright (1991) and its intellectual descendants. The crucial economic elements of this model are trading risk (the arrival of trading opportunities to individuals is stochastic) and decentralization (monetary exchange takes place in spatially separated pair-wise meetings). The former assumption is essentially equivalent to assuming that individuals face shocks to their marginal utilities of consumption and to their labor productivities. Not all basic literature research follows this basic paradigm. However, basic literature typically incorporates at least one of these two elements. 
This modeling approach puts the following question at center stage: In the presence of trading risk and/or pair-wise trade, what are the nature of optimal monetary policy and the costs of deviating from the optimal policy? The authors discuss models in which money is the only asset, followed by models in which money coexists with assets that may have a higher rate of return. One of the important lessons of applied literature is that allowing the government to use other tax instruments may have important implications for optimal monetary policy.

For the basic literature discussion, the Friedman rule is analyzed in terms of 3 models: "heterogeneity", "bargaining", and "the coexistence problem".

\section{The Friedman Rule And Heterogeneity}

Bhattacharya et al. (BHM, 2005) emphasizes that the basic inter-temporal inefficiency argument underlying the Friedman rule ignores distributional effects. The BHM study emphasizes that the validity of the Friedman rule depends crucially on the nature of other taxes and transfers available to the government. In Lagos and Wright (2005), agents' future trading opportunities end up being unaffected by their luck within the current decentralized market.

Matters are very different in Green and Zhou's (2005) paper. They study a world in which agents experience idiosyncratic shocks to their marginal utilities of consumption and endowments; the shocks are independent and identically distributed both over time and over agents. Green and Zhou are interested in the efficiency properties of what they term monetary mechanisms. Green and Zhou prove two results. First, if agents are sufficiently patient, a laissez faire monetary mechanism (no money growth) is nearly efficient. Second, there exist environments in which inflationary monetary mechanisms are efficient and contraction monetary mechanisms are not. Then, as in da Costa and Werning (2003), any necessary redistributions of wealth can be done using taxes or transfers.

\section{The Friedman Rule And Bargaining}

The most current basic literature focuses on model economies in which agents are randomly paired in each period. There is no centralized Walrasian market. Instead, as originally modeled by Shi (1995) and Trejos and Wright (1995), prices are determined through bargaining between the two matched parties. Using two different approaches, Lagos and Wright (2005) and Shi (1997) have constructed models in which agents are essentially insured against the trading risk present in the standard random-matching model. Both Shi (1997) and Lagos and Wright (2005) find that the Friedman rule is the optimal monetary policy. Head and Kumar (2005) enrich the Shi (1997) model by allowing buyers to choose to see multiple prices and choose the seller with the lowest price. Lagos and Rocheteau (2005) study two types of price determination: competitive search equilibrium and Nash bargaining. Rocheleau and Wright (2005) also study optimal monetary policy in the Lagos-Wright (2005) model under alternative forms of price determination.

The general lesson of these papers is that the nature of price determination in decentralized trade seems to have nontrivial qualitative and quantitative effects on the welfare costs of inflation. Again, though, the welfare analyses in these papers is limited by the absence of other taxes/subsidies and other assets.

\section{The Friedman Rule And The Coexistence Problem}

Basic literature focuses on optimal monetary policy in model economies in which money is the only asset. Applied literature places importance on including other assets in the analysis. Of course, any multiple-asset model of money must be consistent with two key facts. First, money has a lower return than other, apparently similar, assets (like government bonds). Second, the size of the return differential depends on monetary policy (it is higher in highinflation environments). It has proven difficult in the context of the basic literature to generate these facts as equilibrium phenomena.

Shi (2005) presents one argument: The government is committed to accepting only money, not unredeemed bonds, for a subset of the goods that it purchases.

Kiyotaki and Moore (2005) show that if the enforcement constraint is sufficiently tight, money is valued and has a lower return than land because the agents' borrowing constraints bind whenever they have an investment 
opportunity. The Friedman rule is optimal in their setting. Zhu and Wallace (2004) argue that rate-of-return dominance can be understood as the result of buyers and sellers following a particular bargaining norm in pair-wise meetings.

All three models capture the fact that money has a lower return in equilibrium than other assets, without simply imposing this conclusion through an ad hoc device like a transaction technology or preferences for real balances. Just like the models in the applied literature, they all imply that the Friedman rule is optimal. Of course, these models are merely first steps. It will be interesting to see whether the Friedman rule in fact generalizes to other (as yet not invented) basic models that feature rate-of-return dominance.

The basic literature must also confront the problem originally posed by Phelps (1973). Suppose that the government has to raise a certain amount of revenue (for expenditures or redistribution) through a variety of distortion means. How should it allocate those distortions across its various instruments? It is not at a1l obvious that the Friedman rule will be the answer to this question in the context of the models set forth in the basic literature.

\section{Conclusions From Basic Literature}

The main message of the applied literature is that if the government has sufficient instruments, the Friedman rule is optimal. The government should correct other inefficiencies using its other instruments. The absence of an explicit micro-foundation for the coexistence of money and bonds in the underlying models makes this policy prescription less compelling. Although a large amount of progress has been made, there are still two crucial weaknesses in the basic literature. First, the literature has so far not included other forms of taxation besides the inflation tax. Second, the literature is just beginning to grapple with the key question of coexistence of expensive money and cheap bonds.

\section{LOOKING AHEAD}

To provide a credible welfare analysis of monetary policy, basic literature needs to build models with two key elements. First, the government must be allowed to use non-inflationary tax instruments. Second, in equilibrium, agents should hold both money and other assets with potentially higher returns that depend on the specification of monetary policy. It is impossible to know what the future of monetary theory holds. But there are four directions the authors hope will be pursued by scholars: decentralized exchange, nominal rigidities, implementation, and dialogue between scholars of applied and basic approaches to international monetary policy.

\section{Decentralized Exchange}

Following Kiyotaki and Wright (1991), modern monetary theory has put a great deal of emphasis on decentralized exchange, in which trade takes place in small groups. Price determination is no longer Walrasian in such models. Many traditional macroeconomists feel that the field has made considerable progress using the competitive paradigm, and view the emphasis on decentralized exchange with a great deal of suspicion.

First, Lagos and Wright (2005) have shown that if prices are determined by Nash bargaining, the costs of inflation associated with a given "money demand curve" depend in a quantitatively significant fashion on the bargaining power of the seller. Their results are reinforced by the work of Head and Kumar (2005) and Lagos and Rocheteau (2005). Bargaining matters for monetary economics.

Second, it was traditional in the random-matching literature to assume that all trading pairs use the same bargaining protocol. Ravikumar and Wallace (2001) and Zhu and Wallace (2004) relax this assumption. The premise of these papers is that in models with pair-wise trade, the correct notion of the core imposes relatively little discipline: Agents can only form blocking pairs, not blocking coalitions of arbitrary size.

It is important not to make too much of these results. They certainly do not demonstrate that one learns nothing from analyses based on the Walrasian auctioneer. But the Walrasian auctioneer abstracts from many elements of real-world trade. The authors are convinced from the aforementioned papers that one will continue to learn a lot 
about monetary economics, and economics more generally, by studying the implications of another kind of abstraction: All trade takes place in small groups.

\section{Nominal Rigidities}

From the work of Bils and Klenow (2004), as well as others, we know that firms change prices only infrequently. Infrequent price changes should emerge as an equilibrium phenomenon. In a recent working paper, Hall (2004) shows how sticky wages lie in the pair-wise core of an economy of workers and employers.

\section{Implementation}

The problem of implementation has received a myriad of attention in the applied money literature. One may know that the government can set its monetary and fiscal variables in such a way that a desirable outcome is equilibrium. But what if other much less desirable outcomes are also equilibrium? The need is to construct specifications of policy that allow desirable outcomes to emerge as equilibrium.

\section{Dialogue}

Economic research into money and monetary policy proceeds in many different ways. That is as it should bemonetary economics is a complex subject that warrants a number of different approaches. But the lack of contact and dialogue between the various groups of scholars is mystifying.

\section{REFERENCES}

1. Atkinson, A. and J. Stiglitz, 1976. The Design of Tax Structure: Indirect vs. Direct Taxation, Journal of Public Economics, pp. 55-75.

2. Berensten, A., G. Camera, and C. Waller, 2005. The Distribution of Money Balances and the Non-Neutrality of Money, International Economic Review, pp. 465-487.

3. Bhattahaarya, J., J. Haslag, and A. Martin, 2005. Heterogeneity, Redistribution, and the Friedman Rule, International Economic Review, pp. 437-454.

4. Bils, M. and P. Klenow, 2004. Some Evidence on the Importance of Sticky Prices, Journal of Political Economy, pp. 947-985.

5. Chari, V., L. Christiano, and P. Kehoe, 1996. Optimality of the Friedman Rule in Economics with Distorting Taxes, Journal of Monetary Economics, pp. 203-223.

6. Corretia, I. and P. Telis, 1999. The Optimal Inflation Tax, Review of Economic Dynamics 2, pp. 325-346.

7. Corretia, I., J. Nicolini, and P. Teles, 2002. Optimal Fiscal and Monetary Policy: Equivalence Results, Mimeo, Federal Reserve Bank of Chicago, 2002.

8. da Costa, C. and I. Werning, 2003. On the Optimality of the Friedman Rule with Heterogeneous Agents and Non-linear Income Taxation, Manuscript, http://epge.fgv.br/portal/arquivo/1520.pdf.

9. Diamond, P. and J. Mirrlees, 1971. Optimal Taxation and Public Production I: Production Efficiency, American Economic Review, pp. 8-27.

10. Friedman, M., 1969. The Optimum Quantity of Money, in The Optimum Quantity of Money and Other Essays, Chicago: Aldine, pp. 1-50.

11. Golosov, M., N. Kocherlakoia, and A. Tsyvinski, 2003. Optimal Indirect and Capital Taxation, Review of Economic Studies, pp. 569-587.

12. Green, E. and R. Zhou, 2005. Money as a Mechanism in a Bewley Economy, International Economic Review, pp. 351-371.

13. Hall, R., 2004. Employment Efficiency and Sticky Wages: Evidence from Flows in the Labor Market, Mimeo, Stanford University.

14. Head, A. and A. Kumar, 2005. Price Dispersion, Inflation, and Welfare, International Economic Review, pp. 533-572.

15. Joyce, W. and S. Woehrle, 2005. Some Thoughts on International Monetary Policy, symposium paper presentation at the London College of Economics.

16. Kimbrough, K., 1986. The Optimum Quantity of Money Rule in the Theory of Public Finance, Journal of 
Monetary Economics, pp. 277-284.

17. Kiyotaki, N. and J. Moore, 2005. Liquidity and Asset Prices, International Economic Review, pp. 317-349.

18. Kiyotaki, N. and R. Wright, 1989. On Money as a Medium of Exchange, Journal of Political Economy, pp. 927-954.

19. Kiyotaki, N. and R. Wright, 1991. A Contribution to the Pure Theory of Money, Journal of Economic Theory, pp. 215-235.

20. Lagos, R. and G. Rocheteau, 2005. Inflation, Output, and Welfare, International Economic Review, pp. 495522.

21. Lagos, R. and R. Wright, 2005. A Unified Framework for Monetary Theory and Policy Analysis, Journal of Political Economy, forthcoming.

22. Lucas, R., Jr. and N. Stokey, 1987. Money and Interest in a Cash-in-Advance Economy, Econometrica, pp. 491-513.

23. Phelps, E., 1973. Inflation in the Theory of Public Finance, Swedish Journal of Economics, pp. 67-82.

24. Ravikumar, B. and N. Wallace, 2001. A Benefit of Uniform Currency? Mimeo, Pennsylvania State University.

25. Rocheteau, G. and R. Wright, 2005. Money in Search Equilibrium, Competitive Equilibrium, and Competitive Search Equilibrium, Econometrica, pp. 175-202.

26. Schmitt-Grohe, S. and M. Uribe, 2004. Optimal Fiscal and Monetary Policy under StickyPrices, Journal of Economic Theory, pp. 183-209.

27. Shi, S., 1995. Money and Prices: A Model of Search and Bargaining, Journal of Economic Theory, pp. 467496.

28. Shi, S. A Divisible Search Model of Fiat Money, Econometrica, pp. 75-102.

29. Shi, S., 2005. Nominal Bonds and Interest Rates: The Case of One-Period Bonds, International Economic Review, pp. 579-612.

30. Sidrauski, M., 1967. Rational Choice and Patterns of Growth in a Monetary Economy, American Economic Review, pp. 534-544.

31. Trejos, A. and R. Wright, 1995. Search, Bargaining, Money and Prices, Journal of Political Economy, pp. 118-141.

32. Zhu, T. and N. Wallace, 2004. Co-Existence of Money and Higher-Return Assets a Bargaining Norm, Mimeo, Pennsylvania State University. 
International Business \& Economics Research Journal - February 2007

Volume 6, Number 2 NOTES 